\title{
TERAPI AKUPRESUR PADA TEKANAN DARAH PENDERITA HIPERTENSI: STUDI LITERATUR
}

\author{
Nur Dina Kamelia ${ }^{1}$, Anita Dwi Ariyani ${ }^{2}$, Rudiyanto*3 \\ ${ }^{1}$ Mahasiswi Program Studi S1 Keperawatan STIKES Banyuwangi \\ ${ }^{2,3}$ Dosen Program Studi S1 Keperawatan STIKES Banyuwangi
}

\section{${ }^{*}$ Correspondence: Rudiyanto}

Email: rudiyanto.roqy@gmail.com

\begin{abstract}
ABSTRAK
Latar Belakang: Salah satu penyebab kematian nomor satu di dunia setiap tahun dan faktor risiko ketiga kematian dini adalah hipertensi. Pengobatan untuk hipertensi dapat diberikan melalui terapi non farmakologi salah satunya yaitu dengan terapi akupresur. Tujuan dari literature review untuk mengetahui pengaruh terapi akupresur terhadap tekanan darah pada pasien dengan hipertensi.

Metode: Study ini menggunakan literature review dengan metode pencarian artikel menggunakan PICOTT question pada database Trip, PubMed, dan Google Scholar. Penelusuran dibatasi pada artikel teks lengkap, penelitian asli, jurnal nasional dan internasional, yang diterbitkan pada tahun 2015-2020. Ditemukan 84 artikel dari semua basis data, 63 artikel Google scholar, 17 artikel PubMed, 4 artikel Trip.

Hasil: Peneliti menemukan 10 artikel yang sesuai dengan kriteria inklusi dan eksklusi. Hasil literature review menunjukkan hasil dari setiap artikel yaitu terdapat pengaruh terapi akupresur terhadap tekanan darah pasien dengan hipertensi di dalam 8 artikel, sedangkan ada 2 artikel yang tidak ada pengaruh terapi akupresur terhadap tekanan darah pasien dengan hipertensi.

Kesimpulan: Terapi akupresur sebagai salah satu terapi komplementer diharapkan mampu untuk diaplikasikan perawat dalam menurunkan tekanan darah pada penderita hipertensi.
\end{abstract}

Kata Kunci: Terapi Akupresur, Tekanan Darah, Hipertensi

\section{ABSTRACT}

Background: One of the leading causes of death in the world every year and the third risk factor for premature death is hypertension. Treatment for hypertension can be given through non-pharmacological therapy, one of which is acupressure therapy. The purpose of the literature review was to determine the effect of acupressure therapy on blood pressure in patients with hypertension.

Method: This study used a literature review with article search method using PICOTT questions on the Trip, PubMed, and Google Scholar databases. The search was limited to full-text articles, original research, national and international journals, published in 20152020. It was found 84 articles from all databases: 63 are Google scholar articles, seventeen are PubMed articles, and four are Trip articles.

Results: Researchers found 10 articles that matched the inclusion and exclusion criteria. The results of the literature review showed that acupressure therapy had effect on the blood pressure of patients with hypertension as shown in eight articles, while the other two articles indicated that acupressure therapy had no effect on the blood pressure of patients with hypertension. The results of literature review showed that acupressure therapy could affect blood pressure in hypertensive patients.

Conclusion: Nurses should apply acupressure therapy as a complementary therapy in reducing blood pressure in hypertensive sufferers.

Keywords: Acupressure Therapy; Blood Pressure; Hypertension 


\section{PENDAHULUAN}

Salah satu penyakit atau gangguan kardiovaskuler adalah hipertensi. Hipertensi merupakan penyakit yang tidak menular atau biasa disebut silent killer dan juga menjadi masalah serius di Indonesia dan dunia (Haryani \& Misniarti, 2020). Hipertensi (tekanan darah tinggi) adalah suatu kondisi yang terjadi ketika tekanan pada pembuluh darah meningkat dengan sistol $>140 \mathrm{mmHg}$ dan diastole $>90 \mathrm{mmHg}$ (Aminuddin, Sudarman \& Syakib, 2020). Adapun cara menurunkan tekanan darah adalah akupresur yang merupakan pengembangan dari terapi pijat yang berasal dari akupunktur (Pujiastuti \& Azaria, 2019).

World Health Organization (WHO) melaporkan bahwa sekitar $26,4 \%$ penduduk dunia mengalami hipertensi (Yonata \& Pratama, 2016). Berdasarkan RISKESDAS (2018) menyebutkan bahwa prevalensi hipertensi berdasarkan hasil pengukuran pada penduduk usia 18 tahun adalah 34,1\%, tertinggi di Kalimantan Selatan (44,1\%), sedangkan terendah di Papua (22,2\%). Diperkirakan jumlah kasus hipertensi di Indonesia adalah 63.309.620 orang, sedangkan angka kematian akibat hipertensi di Indonesia adalah 427.218 kematian. Hipertensi biasanya terjadi pada kelompok usia 31-44 tahun (31,6\%), usia 45-54 tahun $(45,3 \%)$, usia $55-64$ tahun $(55,2 \%)$ (RISKESDAS, 2018). Dari prevalensi hipertensi sebesar $34,1 \%$ diketahui $8,8 \%$ orang terdiagnosis hipertensi, $13,3 \%$ tidak minum obat dan $32,3 \%$ tidak rutin minum obat (RISKESDAS, 2018). Kota Surabaya termasuk dalam lima besar kota atau kabupaten di Jawa Timur yang memiliki jumlah penderita hipertensi tertinggi yaitu 45.014 jiwa atau 10,43\% (Dinkes Jatim, 2017). Di Provinsi Jawa Timur persentase hipertensi sebesar $22,71 \%$ atau sekitar 2.360 .592 penduduk, dengan proporsi laki-laki sebesar $18,99 \%$ (808.009 penduduk) dan perempuan sebesar 18,76\% (1.146.412 penduduk) (Dinkes Jatim, 2017). Di Kabupaten Banyuwangi terdapat 92.934 kasus penderita hipertensi (Dinas Kesehatan, 2019).

Hipertensi dapat disebabkan oleh faktor-faktor pendukung seperti bertambahnya usia, obesitas, stres psikologis, merokok, keturunan, dan kebiasaan makan atau pola konsumsi yang tidak sehat (Sella \& Novayelinda, 2018). Beberapa pasien yang menderita hipertensi biasanya mengalami tanda dan gejala seperti sakit kepala parah, penglihatan kabur, telinga berdenging, kebingungan, detak jantung tidak teratur, nyeri dada, pusing, lemas, kelelahan, kesulitan bernafas, gelisah, mual atau muntah, epistaksis, darah dalam urin (hematuria), peningkatan vena jugularis dan penurunan kesadaran (Haryani \& Misniarti, 2020). Komplikasi hipertensi adalah stroke trombolitik dan hemoragik, retinopati, infark miokard akut, gagal jantung, proteinuria, gagal ginjal, dan penyakit vaskular aterosklerotik (Saputra \& Mulyadi, 2020). Komplikasi yang serius adalah kematian akibat sumbatan dan pecahnya pembuluh darah otak (Yanti, Mahardika \& Prapti, 2016). Jenis pengobatan hipertensi dibagi menjadi dua, yaitu terapi farmakologis dan terapi nonfarmakologis. Terapi farmakologi adalah pengobatan dengan menggunakan obat-obatan yang dapat membantu menurunkan dan menstabilkan tekanan darah. Obat yang biasa digunakan adalah kaptopril (Santoso, Susilo \& Pranata, 2014). Terapi nonfarmakologi digunakan untuk menurunkan tekanan darah tanpa ketergantungan obat dan efek samping seperti akupresur (Majid, 2017).

Terapi akupresur adalah suatu bentuk fisioterapi dengan memberikan pijatan dan stimulasi pada titik atau titik tertentu pada tubuh (Saputra \& Mulyadi, 2020). Akupresur dilakukan dengan cara menekan atau memberikan getaran selama 15-20 detik pada setiap tempat atau titik (Aminuddin, Sudarman \& Syakib, 2020). Teknik ini sangat efisien dan relatif aman karena tidak dilakukan secara invasif atau melukai kulit tubuh. Manfaat akupresur termasuk membantu dalam manajemen stres, menenangkan ketegangan saraf, meningkatkan relaksasi tubuh, meningkatkan sirkulasi darah sehingga proses oksigenasi ke jaringan lebih lancar, dan sangat bermanfaat dalam mengurangi insomnia. Teknik terapi ini menggunakan jari yang dilakukan pada titik-titik yang berhubungan dengan hipertensi (Afrila \& Dewi, 2015).

Pijat pada titik-titik tertentu dalam terapi akupresur dapat merangsang gelombang saraf sehingga dapat meningkatkan aliran darah, mengendurkan kejang, dan menurunkan tekanan darah (Afrila \& Dewi, 2015). Pernyataan ini didukung oleh penelitian yang dilakukan 
oleh Majid (2016) tentang terapi akupresur serta didapatkan bahwa akupresur memberikan efek penurunan tekanan darah lansia. Penelitian ini juga sejalan dengan penelitian yang dilakukan oleh Widodo (2014) yang berjudul Pengaruh Terapi Akupresur pada Pasien Hipertensi di Klinik Sinergi Mind Healt Surakarta. Hasil penelitian Widodo (2014) menunjukkan bahwa terdapat pengaruh terapi akupresur terhadap penurunan tekanan darah pada penderita hipertensi.

\section{METODE}

Metode yang digunakan pada penelitian ini adalah literature review. Pencarian data dilakukan pada tiga database yaitu Google Scholar, PubMed Trip dengan basis pencarian artikel nasional dan internasional. Framework yang digunakan yaitu PICOTT yang merupakan akronim dari 4 komponen : P (Population), I (Intervention), C (Comparation), O (Outcome), $\mathrm{T}$ (Type of time) dan $\mathrm{T}$ (Type of study).

Tabel 1. PICOTT

\begin{tabular}{|c|c|c|}
\hline PICOTT & Pertanyaan Klinis & Kata Kunci \\
\hline Population & Pasien dengan hipertensi & internasional: \\
\hline Intervention & Terapi akupresur & "acupressure \\
\hline Comparison & Selain terapi akupresur & pressure", "hypertension", \\
\hline Outcome & Perubahan tekanan darah & blood pressure". \\
\hline Type of Time & $2015-2020$ & nasional: \\
\hline Type of Study & Penelitian eksperimental & $\begin{array}{l}\text { akupresur", } \\
\text { "hipertensi", "tekananan darah tinggi" }\end{array}$ \\
\hline
\end{tabular}

\section{HASIL}

Setelah dilakukannya pencarian artikel dari database Google Scholar, PubMed dan Trip dengan menggunakan beberapa kata kunci yang telah ditentukan dan diperoleh artikel sebanyak 84 artikel yang sesuai dengan kata kunci. Kemudian dilakukannya pemilihan dalam rentang waktu yang ditentukan dan artikel full teks telah didapatkan sebanyak 25 artikel. Setelah itu dilanjutkan pemilahan judul dan judul yang tidak sesuai inklusi maka tidak digunakan. Hasil akhir yang diperoleh adalah 10 artikel.

\section{PEMBAHASAN}

\section{Tekanan darah sebelum dan sesudah terapi akupresur}

Hasil penelitian terhadap sepuluh literatur menunjukkan bahwa tekanan darah sebelum diberikan terapi akupresur berada pada kategori hipertensi level $1(70 \%)$ dan hipertensi level $2(30 \%)$. Hasil penelitian terhadap 10 literatur ditemukan perubahan rata-rata tekanan darah pada pasien hipertensi setelah diberikan terapi akupresur. Perubahan rata-rata tekanan darah pada sistol adalah 4-41 $\mathrm{mmHg}$ dan pada diastol adalah 4-16 mmHg.Hipertensi dipengaruhi oleh beberapa faktor predisposisi, antara lain usia dan jenis kelamin. Penyebab lain dari hipertensi adalah konsumsi garam yang tinggi, kebiasaan merokok, olahraga, dan gangguan tidur. Dengan beberapa penyebab hipertensi di atas, maka diperlukan sebuah solusi. Salah satu solusi yang dapat diberikan adalah terapi akupresur. Terapi akupresur merupakan teknik pijat yang dapat memberikan rasa rileks sehingga membuat tekanan darah menurun. Setelah diberikan terapi akupresur, ternyata terjadi perubahan tekanan darah. Delapan artikel (80\%) menjelaskan bahwa ada perubahan tekanan darah dari hipertensi level 2 (sedang) menjadi hipertensi level 1 (ringan) dan dua artikel menjelaskan bahwa tidak ada perubahan tekanan darah karena faktor jenis kelamin. Pada kedua artikel tersebut responden wanita lebih banyak dibandingkan responden pria dan memasuki fase menopause sehingga pengaruh faktor hormonal tidak menyebabkan perubahan tekanan darah. Faktor-faktor tersebut dapat mempengaruhi kesamaan tingkat tekanan darah sebelum dan sesudah akupresur. 


\section{Titik-titik akupresur}

Akupresur adalah metode pengobatan yang berasal dari China (Traditional Chinese Medicine) yang biasa disebut dengan pijat akupunktur. Ini adalah metode pemijatan titik akupunktur pada tubuh manusia tanpa menggunakan jarum suntik (Majid, 2017). Teknik ini sangat efisien dan relatif aman karena tidak invasif atau melukai kulit tubuh. Titik-titik yang digunakan sama dengan yang digunakan dalam terapi akupunktur. Titik dominan yang digunakan dalam 10 pasal tersebut adalah titik Lr 3 (Taichong) yang terletak di proksimal pertemuan tulang metatarsal I dan II metatarsal, Sp 6 (Sanyinjao) yang terletak 4 jari di atas malleolus interns, Ki 3 ( Taixi) yang terletak di antara malleolus interns dan tendon Achilles setinggi bagian tertinggi malleolus internal, dan Li 4 (Hegu) yang terletak di sisi tengah radial tulang metakarpal II di dorsum menu. Stimulasi titik-titik tersebut akan menghasilkan enzim endorphin (zat mirip morfin) dari otak yang menimbulkan rasa nyaman dan dapat menurunkan kadar kortisol dalam darah melalui pengaturan aksis HPA (Priyo, Margono \& Hidayah, 2018).

Pemberian stimulus pada titik-titik tersebut akan merangsang saraf sensoris di sekitar titik akupresur menuju sumsum tulang belakang. Kompleks hipofisis ketiga hipotalamus diaktifkan untuk melepaskan endorfin yang dapat memberikan rasa tenang dan nyaman. Kondisi relaksasi ini akan mempengaruhi perubahan tekanan darah. Efek lain dari pengobatan akupresur adalah merangsang pelepasan serotonin, yang berfungsi sebagai neurotransmitter yang membawa sinyal rangsangan ke batang otak yang dapat mengaktifkan kelenjar pineal untuk menghasilkan hormon melatonin. Melatonin juga dapat menurunkan tekanan darah.

\section{Durasi intervensi akupresur}

Durasi terapi akupresur yang paling banyak digunakan dalam sepuluh artikel adalah 10 menit hingga 30 menit dan dilakukan 3 kali seminggu. Terapi akupresur tidak boleh diterapkan pada klien dengan pembengkakan pada titik pijat, lecet pada kulit dan penyakit serius seperti gagal jantung. Seseorang tidak boleh terlalu keras dalam menekan titik-titik saat memberikan pijatan dan tidak boleh membuat pasien kesakitan. Pijat yang tepat harus mampu menciptakan sensasi kenyamanan. Saat Anda dipijat, tubuh menjadi rileks dan otomatis memengaruhi saraf parasimpatis. Hal ini sesuai dengan penelitian Sulton Wariin, Andi Eka Pranata (2018) yang menyatakan bahwa dua puluh responden merasa nyaman dan rileks saat mendapatkan terapi akupresur.

\section{KESIMPULAN}

Tekanan darah sebelum terapi akupresur dikategorikan sebagai hipertensi level 1 (ringan), level 2 (sedang), dan level 3 (berat). Tekanan darah yang dialami responden mengalami penurunan menjadi hipertensi level $1(70 \%)$ dan level $2(30 \%)$. Setelah diberikan terapi akupresur, tekanan darah menunjukkan perubahan. Delapan artikel (80\%) menjelaskan bahwa ada perubahan tekanan darah dari hipertensi level 2 (sedang) menjadi hipertensi level 1 (ringan) dan dua artikel menjelaskan bahwa tidak ada perubahan tekanan darah. Rerata perubahan tekanan darah yang terjadi pada sistol adalah $4-41 \mathrm{mmHg}$ dan pada diastol adalah 4-16 $\mathrm{mmHg}$. Titik dominan yang digunakan dalam sepuluh artikel adalah $\mathrm{Lr} 3$ (Taichong), Sp 6 (Sanyinjao), Ki 3 (Taixi), dan Li 4 (Hegu). Durasi terapi akupresur yang paling banyak digunakan dalam sepuluh artikel adalah sepuluh menit sampai tiga puluh menit dan dilakukan tiga kali seminggu.

\section{DAFTAR PUSTAKA}

Aburto, N. J., Ziolkovska, A., Hooper, L., Elliott, P., Cappuccio, F. P., \& Meerpohl, J. J. (2013). Effect of lower sodium intake on health: Systematic review and meta-analyses. In BMJ (Online). https://doi.org/10.1136/bmj.f1326

AHA. (2019). 2019 ACC / AHA Guideline on the Primary Prevention of Cardiovascular Disease 2019 ACC / AHA Guideline on the Primary Prevention of Cardiovascular Disease. American College of Cardiology/American Heart Association. 
Amin \& Hardhi. (2016). Asuhan Keperawatan Praktis Berdasarkan Penerapan Diagnosa Nanda, Nic, Noc Dalam Berbagai Kasus Jilid 1 [Practical Nursing Care Based on the Application of Nanda, Nic, Noc Diagnosis in Various Cases Volume 1]. Yogyakarta: Mediaction.

Aminuddin, A., Sudarman, Y., \& Syakib, M. (2020). Penurunan Tekanan Darah Penderita Hipertensi Setelah Diberikan Terapi Akupresur [Decreased Blood Pressure of Hypertension Patients After Being Given Acupressure Therapy]. Jurnal Kesehatan Manarang, 6(1), 57. https://doi.org/10.33490/jkm.v6i1.119

Arum, Y. T. G. (2019). Hipertensi pada Penduduk Usia Produktif (15-64 Tahun) [Hypertension in Productive Age Population (15-64 Years)]. HIGEIA (Journal of Public Health Research and Development).

Aziz, A. (2019). Metodologi Penelitian Keperawatan dan Tehnis Analisa Data. Jakarta: Salemba Medika.

Cybulsky, M., Cook, S., Kontsevaya, A. V., Vasiljev, M., \& Leon, D. A. (2016). Pharmacological treatment of hypertension and hyperlipidemia in Izhevsk, Russia. BMC Cardiovascular Disorders, 16(1), 1-10. https://doi.org/10.1186/s12872-016-0300-9

Cisco. (2014). Teaching The Literature Review: A practical approach for college instructor. Teaching and Learning Inquiry, 41-57.

Dermawan, A. C., Setiawati, S., \& Maryam, R. S. (2019). Self-Acupressure To Lower Blood Pressure On Older Adults Withhypertension. Jurnal Riset Kesehatan, 8(2), 1-4.

Dilla, K. A. (2012). Telaah Kritis Artikel Review Sistematik dan Meta Analisis.

Dinas Kesehatan. (2019). Profil Kesehatan Kabupaten Banyuwangi Tahun 2019 [Banyuwangi Regency Health Profile in 2019]. In Profil Kesehatan Kabupaten Banyuwangi.

Dinkes Jatim. (2017). Profil Kesehatan Propinsi Jawa Timur 2017 [East Java Province Health Profile 2017]. Nucleic Acids Research.

Eko Bagus Santoso, A. J. (2015). Perbedaan Tingkat Tekanan Darah Sebelum Dan Sesudah Dilakukan Tindakan Akupresur Pada Penderita Hipertensi Lansia Di Pslu Puger Kabupaten Jember [Differences in Blood Pressure Levels Before and After Acupressure Actions in Elderly Hypertension Patients in Pslu Puger, Jember Regency]. JURNAL KESEHATAN, 3(1), 154-160.

Guo, L., Fu, X., Jiang, Z. M., \& Xu, A. G. (2015). Acupoint massage nursing conducive to improve curative effect of the obesity patients who are complicated with hypertension and are treated by oral drugs. International Journal of Clinical and Experimental Medicine, 8(7), 11727-11733.

Hartono, R. I. (2012). Akupresur Untuk Berbagai Penyakit [Acupressure For Various Diseases]. Yogyakarta: Rapha Publishing.

Haryani, S., \& Misniarti, M. (2020). Efektifitas Akupresure dalam Menurunkan Skala Nyeri Pasien Hipertensi Diwilayah Kerja Puskesmas Perumnas [The effectiveness of acupressure in reducing the pain scale of hypertensive patients in the working area of the Perumnas Health Center]. Jurnal Keperawatan Reflesia, 2(1), 21-30. https://doi.org/10.33088/jkr.v2i1.491

Hasanudin Kep, S. (2015). Wahab Sjahranie Samarinda Tahun 2015 Karya Ilmiah Ners Akhir Ners Disusun Oleh :

Kadir, A. (2018). Hubungan Patofisiologi Hipertensi dan Hipertensi Renal [Pathophysiology Relationship of Hypertension and Renal Hypertension]. Jurnal IImiah Kedokteran Wijaya Kusuma, 5(1), 15. https://doi.org/10.30742/jikw.v5i1.2

Kementerian Kesehatan RI, 2015. "Panduan Akupresur Mandiri Bagi Pekerja Di Tempat Kerja" [Bebast Acupressure Guide for Workers in the Workplace]. Jakarta: Kementrian Kesehatan RI

Kotruchin, P., Imoun, S., Mitsungnern, T., Aountrai, P., Domthaisong, M., \& Kario, K. (2020). The effects of foot reflexology on blood pressure and heart rate: A randomized clinical trial in stage-2 hypertensive patients. Journal of Clinical Hypertension, September, 1-7. 
https://doi.org/10.1111/jch.14103

Lin, G. H., Chang, W. C., Chen, K. J., Tsai, C. C., Hu, S. Y., \& Chen, L. L. (2016). Effectiveness of Acupressure on the Taichong Acupoint in Lowering Blood Pressure in Patients with Hypertension: A Randomized Clinical Trial. Evidence-Based Complementary and Alternative Medicine. https://doi.org/10.1155/2016/1549658

Maharani, M. A., Widodo, S., \& Hartono. (2019). Pengaruh terapi akupresur totok punggung terhadap tekanan darah pada pasien hipertensi di Wilayah kerja Puskesmas Bandarharjo Semarang [The effect of back acupressure in hypertensive patients in the work area of Bandarharjo Public Health Center, Semarang]. Bukan Jurnal Tapi Tugas, 2(Maret), 1-3.

Majid, Y. A. (2017). Terapi Akupresur Memberikan Rasa Tenang Dan Nyaman Serta Mampu Menurunkan Tekanan Darah Lansia [Acupressure Therapy Provides a sense of calm and comfort and is able to reduce blood pressure in the elderly]. Jurnal Aisyah: Jurnal Ilmu Kesehatan.

Martha, K. (2012). Panduan Cerdas Mengatasi Hipertensi [Smart Guide to Overcoming Hypertension]. Yogyakarta: Araska.

Masriadi. (2016). Epidemiologi Penyakit Tidak Menular [Epidemiology of Non-Communicable Diseases]. Jakarta: CV. Trans Info Media.

Menon, M., \& Shukla, A. (2018). Understanding hypertension in the light of Ayurveda. Journal of Ayurveda and Integrative Medicine, 9(4), 302-307. https://doi.org/10.1016/j.jaim.2017.10.004

Nopri Afrila1, Ari Pristiana Dewi, E. (2015). Efektifitas Kombinasi Terapi Slow Stroke Back Massage Dan Akupresur Terhadap Penurunan Tekanan Darah Pada Penderita Hipertensi [The Effectiveness Of Combination Of Slow Stroke Back Massage And Acupressure Therapy On Reducing Blood Pressure In Hypertension Patients]Nopri. Cybrarians Journal.

Norlander, A. E., Madhur, M. S., \& Harrison, D. G. (2018). Correction: The immunology of hypertension [Journal of Experimental Medicine, 215, 1,(2018)] doi: 10.1084/jem.20171773. Journal of Experimental Medicine, $215(2), 719$. https://doi.org/10.1084/jem.2017177301022018c

Nurhayati, N., Azizah, A. N., Kadafi, A., \& Mardiyono, M. (2019). the Effect of Elderly Academic and Acupressure in the Decrease of Hypertension in Posyandu Lansia Srondol Banyumanik Semarang. Jurnal Riset Kesehatan, 8(2), 60. https://doi.org/10.31983/jrk.v8i2.5397

Nursalam. (2016). Metodologi Penelitian IImu Keperawatan [Nursing Research Methodology] (4th ed.; P. L. Peni, ed.). Jakarta: Salemba Medika.

Oliveros, E., Patel, H., Kyung, S., Fugar, S., Goldberg, A., Madan, N., \& Williams, K. A. (2020). Hypertension in older adults: Assessment, management, and challenges. Clinical Cardiology, 43(2), 99-107. https://doi.org/10.1002/clc.23303

Oparil, S., Acelajado, M. C., Bakris, G. L., Berlowitz, D. R., Cífková, R., Dominiczak, A. F., Grassi, G., Jordan, J., Poulter, N. R., Rodgers, A., \& Whelton, P. K. (2018). Hypertension. Nature Reviews Disease Primers, 4. https://doi.org/10.1038/nrdp.2018.14

Parikh. (2017). Association between Liver Disease and Intracranial Hemorrhage. Journal of Stroke and Cerebrovascular Diseases: The Official Journal of National Stroke Association, 25(3), 543-548.

PERHI. (2019). Konsensus Penatalaksanaan Hipertensi 2019 [Hypertension Management Consensus 2019]. Indonesian Society Hipertensi Indonesia.

Pratiwi, R. Y., Situmorang, Y., Sarjana, B., \& Sumanto. (2017). Petunjuk praktisi [Practitioner's Instructions].

Priyo, ., Margono, ., \& Hidayah, N. (2018). Efektifitas Relaksasi Autogenik \& Akupresur Menurunkan Sakit Kepala \& Tekanan Darah Pada Lansia Hipertensi Di Daerah Rawan Bencana Merapi [The Effectiveness Of Autogenic \& Acupressure Relaxation To Reduce Head And Blood Pressure In Hypertension Livers In Merapi Disaster Prison Areas]. 


Profesi (Profesional Islam): Media Publikasi Penelitian.
https://doi.org/10.26576/profesi.258

Pujiastuti, D., \& Azaria, A. D. (2019). Studi Komparatif Masase Punggung Dan Akupresur Terhadap Tekanan Darah Pada Penderita Hipertensi Di Rw 08 Kelurahan Kricak Kecamatan Tegalrejo Yogyakarta 2017 [Comparative Study of Back Massage and Acupressure Against Blood Pressure in Hypertension Patients in Rw 08 Kricak Village, Tegalrejo District, Yogyakarta 2017]. Jurnal Kesehatan, 6(1), 1-8. https://doi.org/10.35913/jk.v6i1.111

RISKESDAS. (2018). Riset Kesehatan Dasar 2018 [Basic Health Research 2018]. Kementrian Kesehatan Republik Indonesia.

Santoso, E. B., Susilo, A. J., \& Pranata, A. E. (2014). Perbedaan Tingkat Tekanan Darah Sebelum dan Sesudah Dilakukan Tindakan Akupresur Pada Penderita Hipertensi Lansia di PSLU Puger Kabupaten Jember [Differences in Blood Pressure Levels Before and After Acupressure Actions for Elderly Hypertension Patients at PSLU Puger, Jember Regency] 154-160.

Saputra, R., \& Mulyadi, B. (2020). Penurunan Tekanan Darah Pada Lansia Penderita Hipertensi Melalui Terapi Spiritual Emotional Freedom Technique (SEFT) dan Akupresur Titik Taichong [Decreasing Blood Pressure in Elderly Patients with Hypertension through Emotional Freedom Technique (SEFT) Spiritual Therapy and Taichong Point Acupressure]. 20(3), 942-945. https://doi.org/10.33087/jiubj.v20i3.1068

Sella, N., \& Novayelinda, R. (2014). Perbandingan Pemberian Hidroterapi Rendam Kaki Air Hangat Dan Pijat Akupresur Terhadap Tekanan Darah Pada Penderita Hipertensi Primer [Comparison Of Giving Hydrotherapy With Warm Water Foot And Acupressure Massage To Blood Pressure In Primary Hypertension Patients] Nur Sella 1, Erwin 2 , Riri Novayelinda 3. 477-484.

Sp, S., Penurunan, T., \& Darah, T. (2018). Di Pstw Jember. Pengaruh Penekanan Titik Akupresur Taixi (Ki3), Sanyinjiao (Sp6) Terhadap Penurunan Tekanan Darah Pada Lansia Dengan Hipertensi Di Pstw Jember [The Effect Of Taixi (Ki3), Sanyinjiao (Sp6) Acupressure Pressure On The Reduction Of Blood Pressure In Lansia With Hypertension In Jember Pstw], 6(2), 1-8.

Sukmiati, \& Khairunnisa. (2017). Hubungan Kecemasan Dengan Derajat Dismenore Pada Remaja Putri [Relationship Of Anxiety With Degrees Of Dismenore In Adolescents].

World Health Organization. (2018). Global Health Estimates 2018: Disease burden by Cause, Sex, by Country and Region, 2000-2016. World Health Organization.

World Health Organization (WHO). (2015). Global TB report 2015. Journal of Chemical Information and Modeling.

Yanti, N. P. E. D., Mahardika, I. A. L., \& Prapti, N. K. G. (2016). Pengaruh Slow Deep Breathing Terhadap Tekanan Darah Pada Penderita Hipertensi Di Wilayah Kerja Puskesmas I Denpasar Timur [The Effect of Slow Deep Breathing on Blood Pressure in Patients with Hypertension in the Work Area of Puskesmas I East Denpasar]. Jurnal Keperawatan Dan Pemikiran IImiah.

Yonata, A., \& Pratama, A. S. P. (2016). Hipertensi sebagai Faktor Pencetus Terjadinya Stroke [Hypertension as a triggering factor for stroke]. Jurnal Majority, 5(3), 17-21. http://juke.kedokteran.unila.ac.id/index.php/majority/article/view/1030

Zarshenas, M., Heydari, M., Dalfardi, B., Golzari, S., \& Habibi, H. (2014). The medieval origins of the concept of hypertension. Heart Views, 15(3), 96. https://doi.org/10.4103/1995-705x.144807 